\title{
Hydroponics of Edible Cactus (Nopalea cochenillifera): Effect of Cladode Size, Fertilizer Concentration and Cultivation Temperature on Daughter Cladode Growth and Development
}

\author{
Takanori HORIBE \\ College of Bioscience and Biotechnology, Chubu University, Kasugai, Aichi 487-8501, Japan
}

(Received February 1, 2019; Accepted April 11, 2019)

\begin{abstract}
Hydroponic culture holds potential advantages for the production of edible cacti, though there have been few studies investigating the effects on growth. This research investigates the effects of cultivation conditions including mother cladode size, fertilizer concentration and temperature on the growth of the edible cactus Nopalea cochenillifera in hydroponic culture. Mother cladode size was positively correlated with daughter cladode growth and development. Total fresh weight of daughter cladodes per mother cladode was highest when a large mother cladode was used, while small mother cladodes produced fewer daughter cladodes. Fertilizer usage was effective in promoting daughter cladode growth and development, though there was little difference in cladode number and length of first daughter cladode among different fertilizer treatments. In addition, we evaluated the effects of cultivation temperature (light and dark period temperatures of $25^{\circ} \mathrm{C} / 15^{\circ} \mathrm{C}, 25^{\circ} \mathrm{C} / 25^{\circ} \mathrm{C}, 35^{\circ} \mathrm{C} / 15^{\circ} \mathrm{C}$, $35^{\circ} \mathrm{C} / 25^{\circ} \mathrm{C}$, and $45^{\circ} \mathrm{C} / 15^{\circ} \mathrm{C}$ ). Cladode growth was promoted at $35^{\circ} \mathrm{C} / 15^{\circ} \mathrm{C}$ and $35^{\circ} \mathrm{C} / 25^{\circ} \mathrm{C}$ leading to an increased harvest of daughter cladodes compared with other treatments. Our results show that mother cladode size, fertilizer concentration and cultivation temperature strongly affect daughter cladode growth and development. Thus, controlling cultivation conditions is important for improving edible cactus productivity and quality when using hydroponics.
\end{abstract}

Keywords : edible cactus, environmental control, hydroponics culture, Nopalea cochenillifera

\section{INTRODUCTION}

Cacti of the genera Opuntia and Nopalea (subfamily Opuntioideae, family Cactaceae) are commonly referred to as nopal cactus or prickly pear, and are major sources of edible fruit. They are also used as a vegetable and as forage in areas where the soils are poor or are becoming poor and where the yield of traditional crops is low (GarcíaSaucedo et al., 2005). For example, the edible stems of cacti are widely consumed as a vegetable in Mexico, Latin America, South Africa, and Mediterranean countries (Stintzing and Carle, 2005; Cruz-Hernández and ParedesLópez, 2010; El-Mostafa et al., 2014). In addition, these plants are used in some countries as a remedy for a variety of health problems including edema and indigestion (ElMostafa et al., 2014). Edible cacti are also produced on a small scale in Japan, where they are produced mainly in Kasugai City, Aichi Prefecture.

Edible cacti are commonly grown in soil or pot culture. The main problems encountered in growing vegetables in soil include soil-borne disease, salt accumulation, and difficulty in fertilizer management (Lakkireddy et al., 2012). In hydroponic culture, plants are grown using nutrient solution (water and fertilizer), with or without the use of an artificial medium. Such a system can avoid the costly and time-consuming task of soil sterilization to prevent soil-borne disease, and enable precise fertilizer management (Wahome et al., 2011; Lakkireddy et al., 2012), resulting in numerous advantages for consumers as well as producers. By using a hydroponic system developed using low-cost materials, edible cactus cultivation can be easily performed anywhere, including in greenhouses, in buildings, as well as in areas experiencing soil stress. A reduction in the labor required for harvesting and management can be achieved by positioning the hydroponic system on raised benches. In addition, such a system would be ideal for use by horticultural hobbyists based in cities, who typically practice soil/pot culture. Apart from its commercial application, hydroponics can also be used in research on the different edible cactus growth variables and their interrelationships. This includes a non-destructive method of studying the root system of edible cacti and any standing crop that is normally hidden below the ground. Thus, there are advantages associated with hydroponic culture that could be exploited for cultivation of edible cacti, although this method is not yet commercially practiced. We have previously shown that edible cacti can be grown in a simple hydroponic culture system using commercially available materials (Horibe and Yamada, 2016; Horibe, 2017). We also believe that the hydroponic cultivation method invented in our laboratory (Horibe, 2017) and the idea of clamping cladodes for attachment to vessels (with further improvement) could lead to the development of a

Corresponding author: Takanori Horibe, fax: +81-92-642-2913, e-mail : t-horibe@isc.chubu.ac.jp 
hydroponic system suitable for the mass production of edible Opuntia in greenhouses and plant factories. However, to our knowledge, few studies have investigated the relationship between the cultivation environment and growth of edible cacti under hydroponic conditions (North et al., 1995).

Understanding the relationship between environmental conditions and cladode growth is important for improving the production and quality of edible cacti. In this study, we cultivated edible cacti using deep flow hydroponic culture and investigated the effect of cultivation conditions including mother cladode size, fertilizer concentration and temperature on cladode growth.

\section{MATERIALS AND METHODS}

\section{Plant materials}

Cladodes of the edible cactus Nopalea cochenillifera (also known as Opuntia 'Maya' in Aichi Prefecture, Japan) were harvested at a commercial cactus farm (Goto saboten) in Aichi Prefecture, Japan. Cladodes were transported under dry conditions to our laboratory within 1 hour and then immediately used in the experiments.

\section{Cladode size treatments}

Cladodes averaging $21 \mathrm{~cm}$ in length, $8 \mathrm{~cm}$ in width, and $1.2 \mathrm{~cm}$ in thickness were harvested and trimmed to different designated sizes, then cultivated in a deep flow hydroponic system. Treatments were: (1) cladode trimmed to $8 \mathrm{~cm}$ (Small); (2) cladode trimmed to $14 \mathrm{~cm}$ (Medium); (3) cladode trimmed to $20 \mathrm{~cm}$ (Large) (Fig. 1). In all treatments, cladodes were attached to a plastic vessel (volume 4.5 L) using an L-shaped plastic bar (L type angle) and clips (Horibe, 2017). The containers were filled with OAT House solution A (fertilizer) with an electrical conductivity of $2.6 \mathrm{dS} \mathrm{cm}^{-1}$. OAT House solution A (OAT Agrio Co., Ltd., Japan) was prepared by dissolving $150 \mathrm{~g}$ of OAT House 1 and $100 \mathrm{~g}$ of OAT House 2 in $100 \mathrm{~L}$ of water, and this was used as the hydroponic nutrient solution. The level of the solution was maintained weekly by topping up with deionized water. Cladodes were grown in a growth chamber maintained at $25^{\circ} \mathrm{C}$ under 14 hours light (photosynthetic photon flux density of $100-110 \mu \mathrm{mol} \mathrm{m}^{-2} \mathrm{~s}^{-1}$ ) and at $15^{\circ} \mathrm{C}$ under 10 hours darkness. Fluorescent lamp was used

(A)

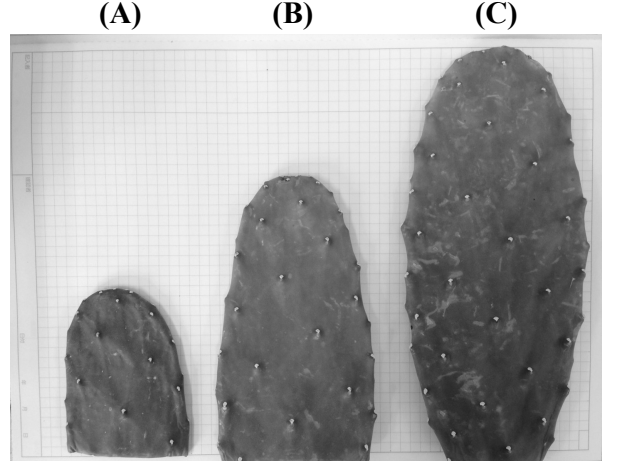

Fig. 1 Photograph showing the different sizes of cladodes used. Cladode trimmed to (A) $8 \mathrm{~cm}$ (Small), (B) $14 \mathrm{~cm}$ (Medium) and (C) $20 \mathrm{~cm}$ (Large). as light source. Relative humidity and $\mathrm{CO}_{2}$ concentration was not controlled. The number of daughter cladodes and their length were measured weekly. Daughter cladodes were harvested at 14 weeks following the start of the treatments.

\section{Fertilizer concentration treatments}

Cladodes averaging $17 \mathrm{~cm}$ long, $7.5 \mathrm{~cm}$ wide, and 1 $\mathrm{cm}$ thick were harvested and trimmed to $16 \mathrm{~cm}$, attached to their pots and cultivated using the deep flow hydroponic culture system described above. In this case, the containers were filled with OAT House solution A (fertilizer) with different electrical conductivities. Treatments were: (1) deionized water (water); (2) OAT House solution A with electrical conductivity of $0.87 \mathrm{dS} \mathrm{cm} \mathrm{cm}^{-1}(\times 1 / 3)$; (3) OAT House solution A with electrical conductivity of $2.6 \mathrm{dS}$ $\mathrm{cm}^{-1}(\times 1)$; (4) OAT House solution A with electrical conductivity of $7.8 \mathrm{dS} \mathrm{cm}^{-1}(\times 3)$. The level of the solution was maintained weekly by topping up with deionized water. Cladodes were grown in a growth chamber maintained at $25^{\circ} \mathrm{C}$ under 14 hours light (photosynthetic photon flux density of $100-110 \mu \mathrm{mol} \mathrm{m} \mathrm{m}^{-2} \mathrm{~s}^{-1}$ ) and at $15^{\circ} \mathrm{C}$ under 10 hours darkness. Fluorescent lamp was used as light source. Relative humidity and $\mathrm{CO}_{2}$ concentration was not controlled. The electrical conductivity in each nutrient solution was measured weekly by EC meter (LAQUAtwin-EC33B; HORIBA, Inc., Kyoto, Japan). The number of daughter cladodes and their length were measured weekly. Daughter cladodes were harvested at 14 weeks following the start of the treatments.

\section{Cultivation temperature treatments}

Cladodes averaging $17 \mathrm{~cm}$ long, $7.5 \mathrm{~cm}$ wide, and 1 $\mathrm{cm}$ thick were harvested and trimmed to $16 \mathrm{~cm}$, attached to their pots and cultivated using the deep flow hydroponic culture system described above. In this case, the containers were filled with OAT House solution A (fertilizer) with an electrical conductivity of $2.6 \mathrm{dS} \mathrm{cm}{ }^{-1}$. The level of the solution was maintained weekly by topping up with deionized water. Cladodes were grown in a benchtop growth chamber maintained under 14 hours light (photosynthetic photon flux density of $70-80 \mu \mathrm{mol} \mathrm{m} \mathrm{m}^{-2} \mathrm{~s}^{-1}$ ) and 10 hours darkness with different cultivation temperatures. Fluorescent lamp was used as light source. Relative humidity and $\mathrm{CO}_{2}$ concentration was not controlled. Treatments during the light and dark periods, respectively, were: (1) $25^{\circ} \mathrm{C}$ and $15^{\circ} \mathrm{C}\left(25^{\circ} \mathrm{C} / 15^{\circ} \mathrm{C}\right)$; (2) $25^{\circ} \mathrm{C}$ and $25^{\circ} \mathrm{C}\left(25^{\circ} \mathrm{C} / 25^{\circ} \mathrm{C}\right)$; (3) 35 ${ }^{\circ} \mathrm{C}$ and $15^{\circ} \mathrm{C}\left(35^{\circ} \mathrm{C} / 15^{\circ} \mathrm{C}\right)$; (4) $35^{\circ} \mathrm{C}$ and $25^{\circ} \mathrm{C}\left(35^{\circ} \mathrm{C} / 25^{\circ} \mathrm{C}\right)$; (5) $45^{\circ} \mathrm{C}$ and $15^{\circ} \mathrm{C}\left(45^{\circ} \mathrm{C} / 15^{\circ} \mathrm{C}\right)$. The number of daughter cladodes and length of the first daughter cladodes were measured weekly. Daughter cladodes were harvested at 14 weeks following the start of the treatments.

Experimental design and statistical analysis

Three cladodes per treatment were used for each treatment. All experiments were repeated three times. The data were subjected to analysis of variance, and differences across means were determined using Tukey's test, with significance defined as $P<0.05$. 
(A) Length

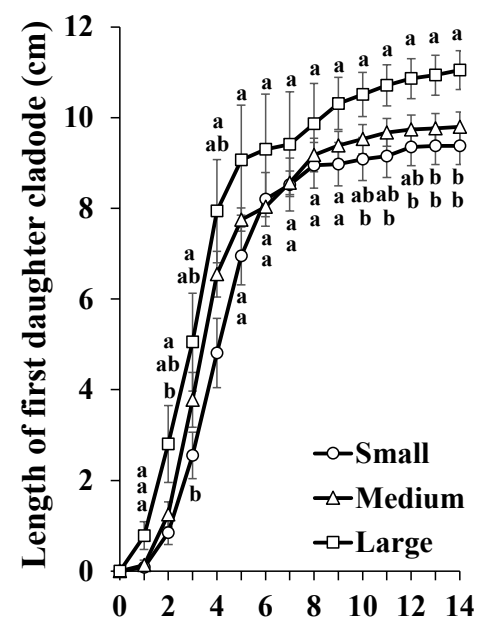

Weeks after treatment (week)
(B) Number

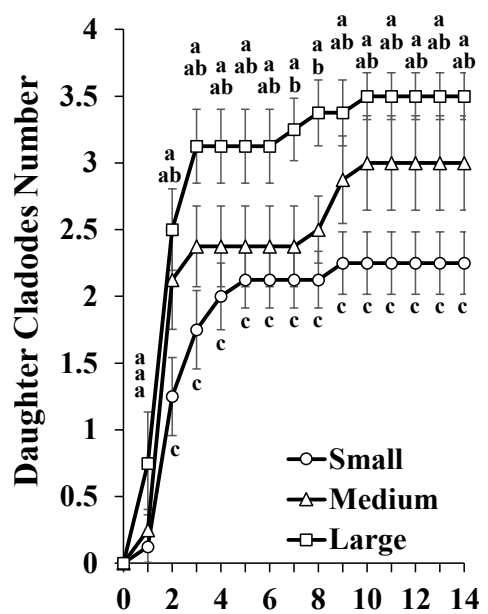

Weeks after treatment (week)

Fig. 2 Length of first daughter cladode (A) and number of daughter cladodes (B) versus mother cladode size. Values are means \pm SE. Means followed by different letters within each week are significantly different at $P<0.05$.

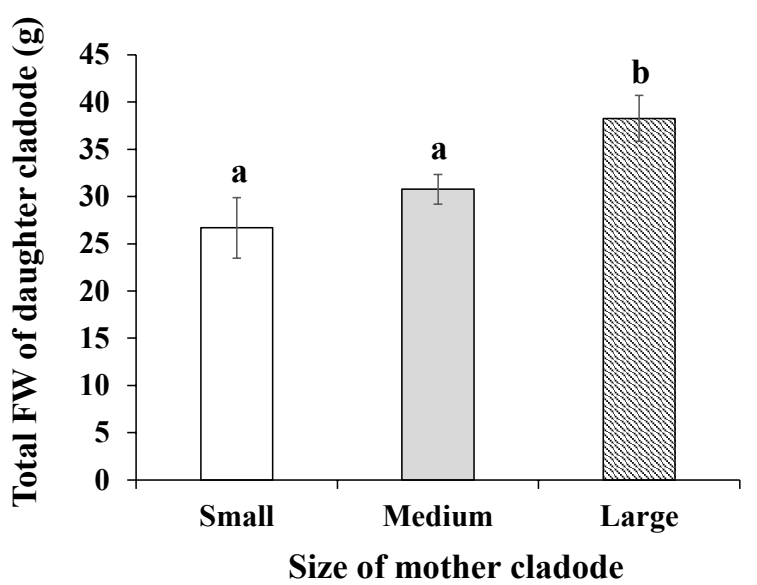

Fig. 3 Total fresh weight (FW) of daughter cladodes per mother cladode for each treatment. Values are means \pm SE. Means followed by different letters are significantly different at $P<0.05$.

\section{RESULTS}

\section{Cladode size treatments}

In all treatments, daughter cladodes developed from mother cladodes. The length of the first daughter cladodes in all treatments increased rapidly during the first 5 weeks after treatment and then showed a more gradual increase from week 6 onward (Fig. 2A). The pattern was similar for the number of daughter cladodes, with a rapid increase during the first 3 weeks (Fig. 2B). The length of the first daughter cladodes and number of daughter cladodes was higher on large mother cladodes than on small mother cladodes, while there were no significant differences between medium and small mother cladodes (Fig. 2). Total fresh weight $(\mathrm{FW})$ of daughter cladodes harvested per mother cladode was significantly higher in large cladodes than in other treatments (Fig. 3). Total FW of daughter cladodes in small and medium mother cladodes were about $70 \%$ and

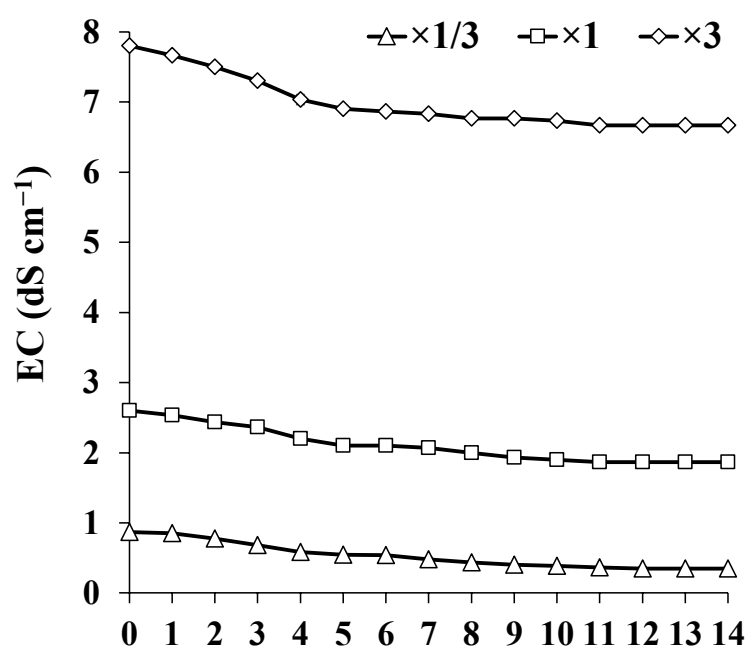

\section{Weeks after treatment}

Fig. 4 Changes in the electrical conductivity (EC) of the hydroponic nutrient solution during the course of the experiment. Values are means $\pm \mathrm{SE}(n=3)$ (note: $\mathrm{SE}$ bars are not shown when masked by the graph symbols).

$80 \%$ of that of large mother cladodes (Fig. 3).

Fertilizer concentration treatments

The electrical conductivity (EC) of the nutrient solution in each treatment gradually decreased during the course of the experiment, although the speed of decrease in EC slowed down after around 5 weeks (Fig. 4). In the water treatment, the length of the first daughter cladode was short and few daughter cladodes emerged compared with the fertilizer treatments, resulting in small total FW of daughter cladodes (Figs. 5 and 6). The length of the first daughter cladode and number of daughter cladodes in different fertilizer treatments did not significantly differ among treatments (Fig. 5), while total FW of daughter cladodes in the $\times 1$ and $\times 3$ treatments was higher than $\times 1 / 3$ treatment (Fig. 6). This is probably because there were differences in daughter cladode width among different fertil- 
(A) Length

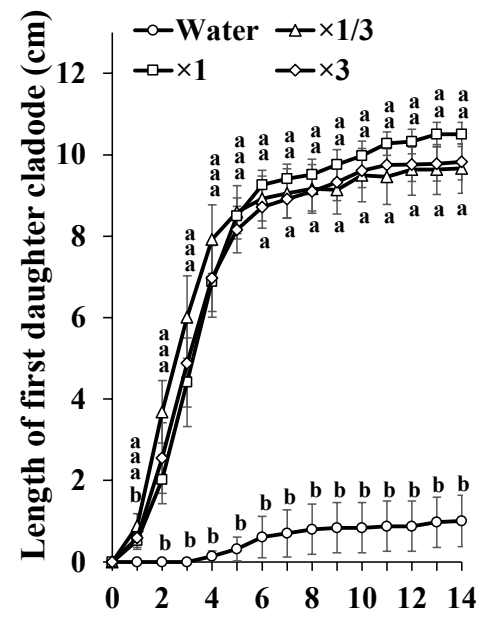

Weeks after treatment (week)
(B) Number

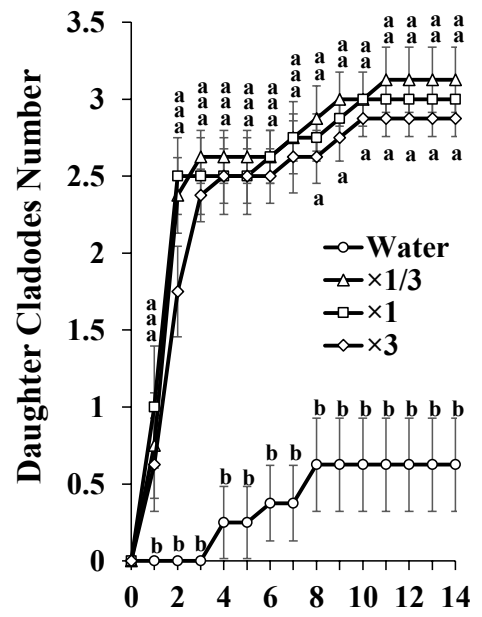

Weeks after treatment (week)

Fig. 5 Length of first daughter cladode (A) and number of daughter cladodes (B) per mother cladode using nutrient solution of different concentrations. Values are means \pm SE. Means followed by different letters within each week are significantly different at $P<0.05$.

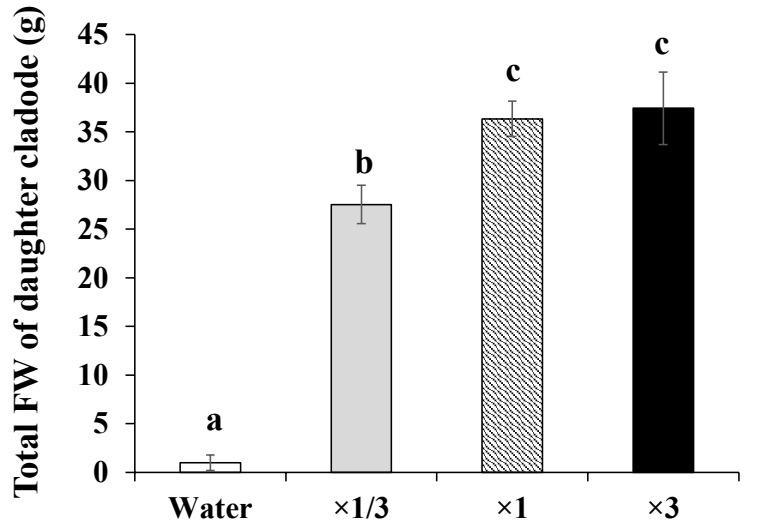

Fig. 6 Total fresh weight (FW) of daughter cladodes harvested per mother cladode in each treatment. Values are means \pm SE. Means followed by different letters are significantly different at $P<0.05$.

izer treatments. The width of daughter cladodes in the $\times 1$ and $\times 3$ treatments might be thicker than $\times 1 / 3$ treatment.

\section{Cultivation temperature treatment}

Under the $45^{\circ} \mathrm{C} / 15^{\circ} \mathrm{C}$ treatment, the mother cladodes withered and died after a short time, and no daughter cladodes appeared. The first daughter cladodes under $35^{\circ} \mathrm{C} / 15^{\circ} \mathrm{C}$ and $35^{\circ} \mathrm{C} / 25^{\circ} \mathrm{C}$ grew longer than for other treatments, and they kept growing until 14 weeks after treatment (Figs. 7 and $8 \mathrm{~A}$ ). In addition, new daughter cladodes developed from daughter cladode on mother cladode under $35^{\circ} \mathrm{C} /$ $15^{\circ} \mathrm{C}$ and $35^{\circ} \mathrm{C} / 25^{\circ} \mathrm{C}$ during the experiment (Fig. 7). Under $25^{\circ} \mathrm{C} / 15^{\circ} \mathrm{C}$ and $25^{\circ} \mathrm{C} / 25^{\circ} \mathrm{C}$, daughter cladode length increased until 9 weeks after treatment and showed very little change after week 10 (Fig. 8A). The number of daughter cladodes did not significantly differ among treatments (Fig. 8B). Total FW of daughter cladodes harvested per mother cladode was significantly higher at $35^{\circ} \mathrm{C} / 15^{\circ} \mathrm{C}$ and $35^{\circ} \mathrm{C} / 25^{\circ} \mathrm{C}$ than at $25^{\circ} \mathrm{C} / 15^{\circ} \mathrm{C}$ and $25^{\circ} \mathrm{C} / 25^{\circ} \mathrm{C}$ (Fig. 9).
(A)

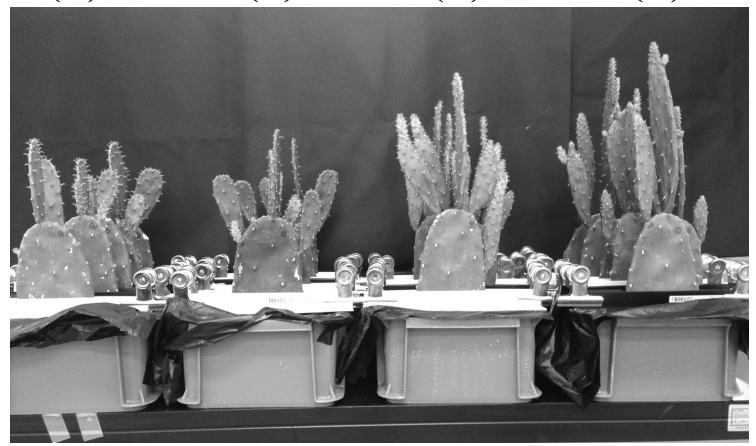

Fig. 7 Photographs of cladodes 10 weeks after treatment. Light (14 hours) and dark (10 hours) period temperatures were (A) $25^{\circ} \mathrm{C}$ and $15^{\circ} \mathrm{C}$, (B) $25^{\circ} \mathrm{C}$ and $25^{\circ} \mathrm{C}$, (C) $35^{\circ} \mathrm{C}$ and $15^{\circ} \mathrm{C}$, and (D) $35^{\circ} \mathrm{C}$ and $25^{\circ} \mathrm{C}$.

\section{DISCUSSION}

In hydroponic culture, plants are grown using a nutrient solution (water and fertilizer) with or without the use of an artificial medium. This technique can be used for the production of edible cacti with added advantages. For example, hydroponics can be used to reduce the nitrate content of vegetables (Wang et al., 2007; Stefanelli et al., 2011), avoiding conversion to harmful nitrites in humans; and to reduce the potassium content (Ogawa, 2012), the intake of which is restricted for dialysis patients. It is also effective in improving quality of crops as well as allowing precise control of fertilizers (Sakamoto et al., 1999). In addition, hydroponics is also a basic method for plant production in plant factories. Efforts to ensure stable production of edible cacti while increasing their nutritive value through environmental control in a plant factory are in progress in our laboratory. Although hydroponic culture conveys many advantages for edible cactus production, there 
(A) Length

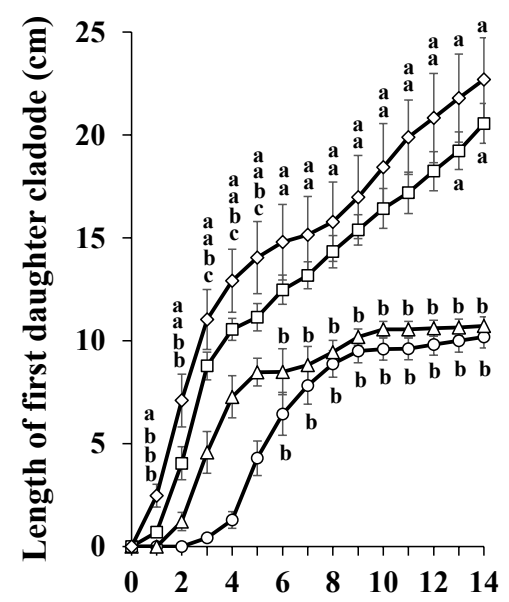

Weeks after treatment (week)
(B) Number

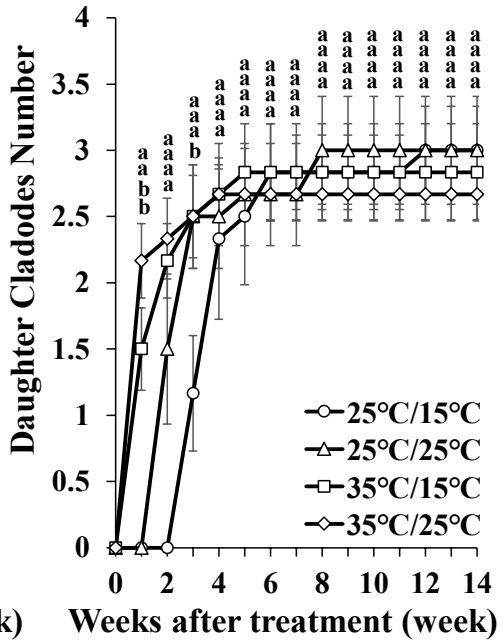

Fig. 8 Length of first daughter cladode (A) and number of daughter cladodes (B) per mother cladode under different cultivation temperatures. Values are means \pm SE. Means followed by different letters within each week are significantly different at $P<0.05$.

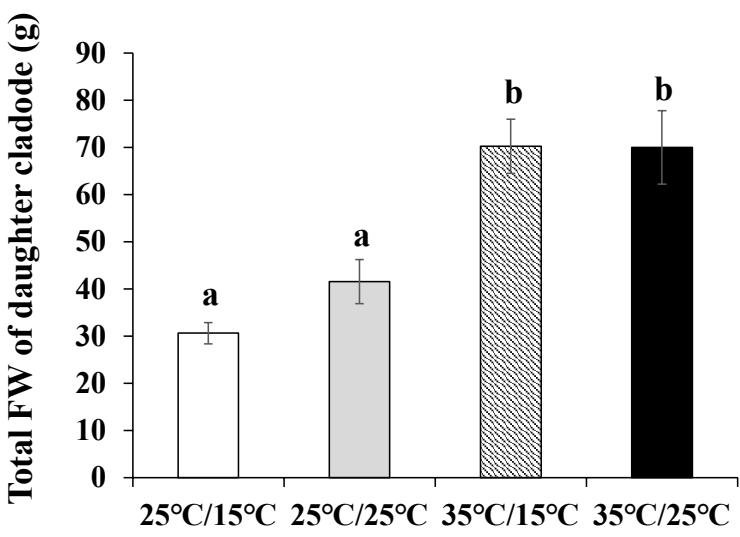

Fig. 9 Total fresh weight (FW) of daughter cladodes harvested per mother cladode under different cultivation temperatures. Values are means \pm SE. Means followed by different letters are significantly different at $P<0.05$.

are few studies investigating the effects of hydroponic culture and cultivation environment on their growth.

Edible cacti are characterized by remarkable adaptation to arid and semi-arid climates. They exhibit crassulacean acid metabolism (CAM), a $\mathrm{CO}_{2}$-concentrating mechanism that potentially leads to higher/optimal temperatures for photosynthesis (Monson, 1989). CAM plants also have certain anatomical modifications that enable them to survive droughts, such as thick cuticles and low stomatal frequency, together with nighttime $\mathrm{CO}_{2}$ uptake (Drennan and Nobel, 2000; Pimienta-Barrios et al., 2005). With respect to cactus growth behavior, daughter cladodes develop from the areoles of the mother cladode and this process is repeated (Pimienta-Barrios et al., 2005). During the early stages of development, daughter cladodes show $\mathrm{C}_{3}$ photosynthesis with daytime stomatal opening (Osmond, 1978; Acevedo et al., 1983) and they import water from the mother cladode (Pimienta-Barrios et al., 2005). In this study, larger mother cladodes produced higher numbers of daughter cladodes and led to higher yield of daughter cladodes (Figs. 2 and 3), most likely because the larger cladodes contained more water and nutrients for daughter cladode growth compared with smaller ones. Our results also showed that an $8 \mathrm{~cm}$ mother cladode was able to produce nearly $70 \%$ of the yield of daughter cladodes in $20 \mathrm{~cm}$ mother cladode (Fig. 3). Short plant height is a desirable trait when using the multistage cultivation systems usually adopted in enclosed-type plant factories because the distance between cultivation bed and light source is often restricted. Thus, cladode size should be chosen according to purpose and cultivation method.

We investigated the effect of fertilizer concentration on the growth of daughter cladodes to determine the appropriate fertilizer concentration for hydroponic cultivation (Figs. 5 and 6). Fertilizer usage was effective in promoting daughter cladode growth and development, and mother cladodes treated with OAT House solution A with electrical conductivity of 2.6 and $7.8 \mathrm{dS} \mathrm{cm}{ }^{-1}$ recorded the largest harvest of daughter cladodes, although overall there was little difference in cladode number (Figs. 5 and 6). Our results showed that $N$. cochenillifera can be grown by hydroponic culture under relatively high EC $\left(7.8 \mathrm{dS} \mathrm{cm}^{-1}\right)$. In general, it is recommended to give low concentrations of fertilizer during the cultivation of cacti and succulents because their growth rates are generally slow. However, the growth rates of edible cacti (Opuntia and Nopalea genera) are fast compared with other cactus species, and it is for this reason that they are used as a vegetable and as fodder in many parts of the world (Stintzing and Carle, 2005; Cruz-Hernández and Paredes-López, 2010; El-Mostafa et al., 2014); it also likely explains the relatively high demand exhibited by $N$. cochenillifera for fertilizer.

Environmental conditions, including temperature, light intensity and fertilizer are reported to affect the elongation of plant stems (Shibutani and Kinoshita, 1968; Hidaka et al., 2014). Therefore, evaluation of the effects of cultivation conditions is essential for improving productiv- 
ity of edible cacti. Comparison of cultivation temperature revealed significant effects on cladode growth and harvest. A temperature of $45^{\circ} \mathrm{C}$ was too high, while daytime and nighttime temperatures of $35^{\circ} \mathrm{C} / 15^{\circ} \mathrm{C}$ and $35^{\circ} \mathrm{C} / 25^{\circ} \mathrm{C}$ were better than $25^{\circ} \mathrm{C} / 15^{\circ} \mathrm{C}$ and $25^{\circ} \mathrm{C} / 25^{\circ} \mathrm{C}$ for daughter cladode growth in $N$. cochenillifera (Figs. 7, 8 and 9). In addition, daytime temperature had a greater effect on the growth of daughter cladodes than nighttime temperature. It is reported that the optimal nighttime temperature for $\mathrm{CO}_{2}$ uptake for Opuntia ficus-indica, an edible cactus that is also used as a vegetable and as forage, is $15^{\circ} \mathrm{C}$ (Nobel and Bobitch, 2002). The optimum temperature for cultivation differs among edible cacti species, then, and it is not clear whether the mother and daughter cladodes in our experiments underwent $\mathrm{C}_{3}$ or CAM photosynthesis. Furthermore, the appropriate cultivation air temperature might differ depending on the cultivation method (e.g., soil versus hydroponic culture) because water availability and temperature around root differ between soil and hydroponic culture.

The present study shows that mother cladode size, fertilizer concentration and cultivation temperature strongly affect daughter cladode growth and development. Manipulating these parameters to promote daughter cladode growth could improve the quality and productivity of edible cacti. More research is needed to further understand the relationship between cultivation conditions and development in edible cacti.

\section{REFERENCES}

Acevedo, E., Badilla, I., Nobel, P.S. 1983. Water relations, diurnal activity changes, and productivity of a cultivated cactus (Opuntia ficus-indica). Plant Physiol. 72: 775-780.

Cruz-Hernández, A., Paredes-López, O. 2010. Enhancement of economical value of nopal and its fruits through biotechnology. J. PACD 12: 110-126.

Drennan, P. M., Nobel, P. S. 2000. Responses of CAM species to increasing atmospheric $\mathrm{CO}_{2}$ concentration. Plant Cell Environ. 23: 767-781.

El-Mostafa, K., El-Kharrassi, Y., Badreddine, A., Andreoletti, P., Vamecq, J., El-Kebbaj, M. S., Latruffe, N., Lizard, G., Nasser, B., Cherkaoui-Malki, M. 2014. Nopal cactus (Opuntia ficus-indica) as a source of bioactive compounds for nutrition, health and disease. Molecules 19: 14879-14901.

García-Saucedo, P. A., Valdez-Morales, M., Valverde, M. E., CruzHernández, A., Paredes-López, O. 2005. Plant regeneration of three Opuntia genotypes used as human food. Plant Cell Tiss. Org. Cult. 80: 215-219.

Hidaka, K., Okamoto, A., Araki, T., Miyoshi, Y., Dan, K., Imamura, H., Kitano, M., Sameshima, K., Okimura, M. 2014. Effect of photoperiod of supplemental lighting with light-emit- ting diodes on growth and yield of strawberry. Environ. Control Biol. 52: 63-71.

Horibe, T., Yamada, K. 2016. Hydroponics culture of edible Opuntia 'Maya': drought stress affects the development of spines on daughter cladodes. Environ. Control Biol. 54: 153156.

Horibe, T. 2017. A cost-effective, simple, and productive method of hydroponic culture of edible Opuntia "Maya". Environ. Control Biol. 55: 171-174.

Lakkireddy, K. K. R., Kasturi, K., Sambasiva, R. K. R. S. 2012. Role of hydroponics and aeroponics in soilless culture in commercial food production. JAST 1: 26-35.

Monson, R. K. 1989. On the evolutionary pathways resulting in $\mathrm{C}_{4}$ photosynthesis and Crassulalacean acid metabolism (CAM). Adv. Ecol. Res. 19: 57-110.

Nobel, P. S., Bobich, E. G. 2002. Environmental biology. In "Cacti. Biology and Uses" (ed. by Nobel, P. S.), University of California Press, Berkeley, p199-210.

North, G. B., Lin Moore, T., Nobel, P. S. 1995. Cladode development for Opuntia ficus-indica (Cactaceae) under current and doubled $\mathrm{CO}_{2}$ concentrations. Am. J. Bot. 82: 159-166.

Ogawa, A., Eguchi, T., Toyofuku, K. 2012. Cultivation methods for leafy vegetables and tomatos with low potassium content for dialysis patients. Environ. Control Biol. 50: 407-414.

Osmond, C. B. 1978. Crassulacean acid metabolism: a curiosity in context. Annu. Rev. Plant Physiol. 29: 379-414.

Pimienta-Barrios, E., Zañudo-Hernandez, J., Rosas-Espinoza, V. C., Valenzuela-Tapia, A., Nobel, P. S. 2005 . Young daughter cladodes affect $\mathrm{CO}_{2}$ uptake by mother cladodes of Opuntia ficus-indica. Ann. Bot. 95: 363-369.

Sakamoto, Y., Watanabe, S., Nakashima, T., Okano, K. 1999. Effects of salinity at two ripening stages on the fruit quality of single-truss tomato grown in hydroponics. J. Hortic. Sci. Biotech. 74: 690-693.

Shibutani, S., Kinoshita, K. 1968. Studies on the ecological adaptation of lettuce. III. The adaptation of great lakes 54 in the growth cabinet in which the temperature is controlled. (in Japanese text with English abstract) Sci. Rep. Fac. Agr. Okayama Univ. 32: 25-34.

Stefanelli, D., Winkler, S., Jones, R. 2011. Reduced nitrogen availability during growth improves quality in red oak lettuce leaves by minimizing nitrate content, and increasing antioxidant capacity and leaf mineral content. AS 2: 477-486.

Stintzing, F. C., Carle, R. 2005. Cactus stems (Opuntia spp.): a review on their chemistry, technology, and uses. Mol. Nutr. Food Res. 49: 175-194.

Wahome, P. K., Oseni, T. O., Masarirambi, M. T., Shongwe, V. D. 2011. Effects of different hydroponics systems and growing media on the vegetative growth, yield and cut flower quality of gypsophila (Gypsophila paniculata L.). WJAS 7: 692-698.

Wang, H., Liang-Huan, W., Min-Yan, W., Yuan-Hong, Z., QinNan, T., Fu-Suo, Z. 2007. Effects of amino acids replacing nitrate growth, nitrate accumulation, and macro element concentrations in pak-choi (Brassica chinensis L.). Pedosphere 17: 595-600. 